\title{
Predicting Symptomatic and Functional Improvements over 1 Year in Patients with First-Episode Psychosis Using Resting-State Electroencephalography
}

\author{
Rinvil Renaldi ${ }^{1,2}$, Minah Kim², ${ }^{2}$, Tak Hyung Lee ${ }^{4}$, Yoo Bin Kwak ${ }^{4}$, Andi J. Tanra', and Jun Soo Kwon ${ }^{2,3,4,5}$ \\ ${ }^{1}$ Department of Psychiatry, Faculty of Medicine, Hasanuddin University, Makassar, Indonesia \\ ${ }^{2}$ Department of Neuropsychiatry, Seoul National University Hospital, Seoul, Republic of Korea \\ ${ }^{3}$ Department of Psychiatry, Seoul National University College of Medicine, Seoul, Republic of Korea \\ ${ }^{4}$ Department of Brain and Cognitive Sciences, Seoul National University College of Natural Sciences, Seoul, Republic of Korea \\ 5 Institute of Human Behavioral Medicine, SNU-MRC, Seoul, Republic of Korea
}

Objective Although early intervention from the beginning of a psychotic episode is essential for a better prognosis, biomarkers predictive of symptomatic and functional improvement in early psychotic disorders are lacking. This study aimed to investigate whether the spectral power of resting-state electroencephalography (EEG) can be used as a predictive marker of the 1-year prognosis in patients with first-episode psychosis (FEP).

Methods Twenty-four patients with FEP and matched healthy control (HC) subjects were examined with resting-state EEG at baseline. The symptomatic severity and functional status of FEP patients were assessed at baseline and reassessed after 1 year of usual treatment. Repeated measures analysis of variance was conducted to compare EEG spectral powers across the groups. Multiple regression analysis revealed EEG spectral powers predictive of symptomatic and functional improvement in FEP patients at the 1-year follow-up.

Results Delta band power in the frontal and posterior regions was significantly higher in patients with FEP than in HCs. Higher delta band power in the posterior region predicted later improvement of positive symptoms and general functional status. Lower delta band power in the frontal region predicted improvement of negative symptoms and general functioning after 1 year.

Conclusion These results suggest that increased delta absolute power is observed from the beginning of psychotic disorders. Furthermore, decreased delta power in the frontal region and increased delta power in the posterior region might be used as a predictive marker of a better prognosis of FEP, which would aid early intervention in clinical practice.

Psychiatry Investig 2019;16(9):695-703

Key Words First-episode psychosis, Prognosis prediction, Quantitative electroencephalography.

\section{INTRODUCTION}

The prognosis of first-episode psychosis (FEP) is highly heterogeneous, ranging from sustained recovery to multiple recurrences and treatment resistance. ${ }^{1}$ Approximately 25\% of patients recover through initial treatment, whereas approximately $50 \%$ of patients experience a fluctuating course with recurrent exacerbation and remission of symptoms, and near-

Received: January 31, 2019 Revised: April 4, 2019

Accepted: June 20, 2019

$\triangle$ Correspondence: Minah Kim, MD, PhD

Department of Neuropsychiatry, Seoul National University Hospital, 101 Daehakro, Jongno-gu, Seoul 03080, Republic of Korea

Tel: +82-2-2072-7211, Fax: +82-2-747-9063, E-mail: verte82@snu.ac.kr

(a) This is an Open Access article distributed under the terms of the Creative Commons Attribution Non-Commercial License (https://creativecommons.org/licenses/by$\mathrm{nc} / 4.0$ ) which permits unrestricted non-commercial use, distribution, and reproduction in any medium, provided the original work is properly cited. ly $25 \%$ of patients are treatment refractory. ${ }^{2}$ Despite these prognostic trajectories, clinicians have made great efforts to improve the prognosis of FEP patients by enlarging the percentage of the first and second groups. Previous studies have consistently shown that a better prognosis is related to a shorter duration of untreated psychosis (DUP), suggesting that the earlier introduction of antipsychotic treatment yields a better prognostic outcome..$^{2-4}$ Although antipsychotic medications can relieve the positive symptoms, prominent adverse effects, such as extrapyramidal symptoms or metabolic syndrome, reduce the quality of life as well as treatment adherence. ${ }^{5-7}$ Therefore, predicting the prognosis from the FEP state would provide valuable information for both the clinicians and patients in deciding whether to provide less or more intensive treatment from the beginning of the intervention.

To date, efforts to predict the prognosis of FEP using clini- 
cal characteristics have not been successful enough. ${ }^{8,9}$ For example, Moos et al. ${ }^{10}$ did not find any significant relationship between the global functional status of the patient at baseline and outcomes after 1 year of treatment. Moreover, Ayesa-Arriola et al. ${ }^{11}$ showed that clinical, cognitive, and premorbid variables were not effective predictors of functional outcomes after a 3-year follow-up in patients with FEP. On the other hand, brain biomarkers related to prognostic outcomes have been suggested in many previous studies. ${ }^{12}$ Lieberman et al. ${ }^{13}$ showed that smaller brain volume loss during the disease course of FEP patients was related to better functional outcomes. In addition, Wood et al. ${ }^{14}$ showed that a lower ratio of $\mathrm{N}$-acetylaspartate (NAA) and choline-containing compounds to creatine and phosphocreatine $(\mathrm{Cr})$ in the frontal cortex was associated with poorer functional outcomes after 1 year. A recent study by our group showed that a larger amplitude of the auditory P300 event-related potential (ERP) component measured at baseline predicted a better prognostic outcome after 1 year in patients with FEP. ${ }^{15}$ The neural correlates of symptomatic or functional changes are more sensitive than the symptomatic approach alone and can reflect the underlying pathophysiologic mechanism. Therefore, efforts to find new brain biomarkers for predicting the prognosis of FEP would be important for both clinical practice and early psychosis research.

In this context, resting-state electroencephalography (EEG) can be a new brain biomarker for predicting the prognosis of FEP because EEG is a direct measure of electrical activities in the brain that are fundamental to neuronal communication. Furthermore, EEG has advantages for clinical application in that it is generally more applicable and less costly than brain imaging or ERP analysis. Quantitative analysis of resting-state EEG can provide the precise power of each EEG frequency to support the findings of their qualitative counterparts. ${ }^{16}$ Previous studies have shown that the delta, theta, and beta frequency power was increased, but the alpha frequency power was decreased in patients with schizophrenia. ${ }^{17}$ In FEP patients, the relationship of increased delta and theta frequency power to severe negative symptoms has been reported. ${ }^{18}$ In particular, delta frequency power measured at frontal sites showed a correlation with negative symptom severity, suggesting that frontal delta power can be a putative biomarker for the negative symptoms of schizophrenia. ${ }^{19}$ However, with regard to the prognosis prediction of FEP using resting-state EEG, only one study group has found that abnormal baseline oscillations in resting-state EEG were associated with poorer prognosis after 1-, 2-, 3-, and 5-year follow-up periods. ${ }^{20-23}$ Unfortunately, these studies defined abnormalities in resting-state EEG oscillations based on qualitative readings of EEG data rather than using quantitative analyses of each frequency band, which can be used in general linear model analysis. Therefore, to the best of our knowledge, there has been no study to predict the symptomatic or functional outcome of FEP patients using restingstate EEG frequency powers.

In the current study, we aimed to investigate whether resting-state EEG spectral powers can predict symptomatic or functional improvement in patients with FEP after 1 year of usual treatment. In line with previous studies, we hypothesized that patients with FEP would show increased theta, delta, and beta frequency power and decreased alpha frequency power compared to healthy control (HC) subjects. We also expected that the altered frequency band power found in FEP patients could be a new biomarker to predict symptomatic or functional improvement during the 1-year follow-up period.

\section{METHODS}

\section{Participants}

In total, 24 patients with FEP and 24 age- and sex-matched $\mathrm{HC}$ subjects participated in this resting-state EEG study. FEP patients were enrolled from the inpatient and outpatient clinics of the Department of Neuropsychiatry at Seoul National University Hospital (SNUH). A patient with FEP was defined as a patient who was diagnosed with schizophreniform disorder, schizophrenia, or schizoaffective disorder using the Structured Clinical Interview for the Diagnostic and Statistical Manual of Mental Disorders, Fourth Edition, Axis I Disorders (SCIDI) and whose duration of psychotic illness was no longer than 2 years. The clinical status of patients with FEP was assessed using the Positive and Negative Syndrome Scale (PANSS) and the Global Assessment of Functioning (GAF) at the time of enrollment and reassessed after 1 year of usual treatment [followup duration (days), mean 393, standard deviation 32, minimum length 347, maximum length 482]. Medication use at baseline and during the follow-up period as well as the DUP was evaluated based on a thorough review of the medical records. The doses of antipsychotics and benzodiazepines were converted into an olanzapine-equivalent $\operatorname{dos}^{24}$ and a lorazepam-equivalent dose ${ }^{25}$ respectively. HC participants were recruited via an internet advertisement and confirmed to have no current and past psychiatric disorders and no family history of psychotic disorders. In both the FEP and HC groups, intelligence quotients (IQ) were examined using the Korean version of the Wechsler Adult Intelligence Scale, ${ }^{26}$ and handedness was assessed using the Annett Handedness Inventory. ${ }^{27}$ Common exclusion criteria included a history of substance misuse (except nicotine), severe head trauma or neurological disorders, medical illness with cognitive sequelae, and intellectual disability (IQ<70).

This study was conducted in accordance with the Declaration of Helsinki and was approved by the Institutional Review 
Board of Seoul National University Hospital. Written informed consent was obtained from all of the participants after a full explanation of the study procedure was provided (H-1810144-983).

\section{EEG recording and processing}

Participants were instructed not to drink coffee, tea or any other stimulant beverages and to refrain from cigarette smoking within the 2 hours before the recording session. The participants were seated in a comfortable single chair located in an isolated shield room with their eyes closed. Continuous EEG recordings were acquired for approximately 5 minutes using a Neuroscan 64 Channel SynAmps system equipped with a 64channel Quick-Cap based on the modified international 1020 system (Neuroscan, El Paso, TX, USA). Both mastoid sites were used as the reference. The EEG signals were digitized at a sampling rate of $1 \mathrm{kHz}$ and online filtered between direct current (DC) and $100 \mathrm{~Hz}$. Eye movement artifacts were monitored by the vertical and horizontal electrooculogram using electrodes below the left eye and near the outer canthus of the left eye. The impedances of all electrodes were less than $5 \mathrm{k} \Omega$.

We used the EEGLAB toolbox to process the EEG data and to perform spectral analysis. ${ }^{28}$ Bad channels were replaced via the linear interpolation of the adjacent channels (up to $7 \%$ per participant). The EEG data were filtered between $0.5 \mathrm{~Hz}$ to $50 \mathrm{~Hz}$. Eye movement artifacts were reduced using the independent component analysis method with the 'sobi' algorithm implemented in the EEGLAB toolbox. By careful visual inspection, approximately 90 seconds of resting-state EEG data composed of stable epochs of 4 seconds without muscle and ocular movement artifacts was selected for spectral analysis. Selected epochs underwent fast Fourier transformations with a Hamming window, and the absolute power $\left(\mu \mathrm{V}^{2}\right)$ of the delta $(1.5-3.5 \mathrm{~Hz})$, theta $(4-7.5 \mathrm{~Hz})$, alpha $\left(8^{-}-14 \mathrm{~Hz}\right)$, and beta $\left(14.5^{-30} \mathrm{~Hz}\right)$ frequency bands of each electrode were acquired. Arithmetic mean values of the absolute powers for each frequency band were obtained from grouped electrodes of frontal (FP1, FPz, FP2), centro-parietal (CP3, CPz, CP4), and posterior $(\mathrm{PO} 7, \mathrm{POz}, \mathrm{PO} 8, \mathrm{Oz})$ regions.

\section{Statistical analysis}

The demographic and clinical characteristics of subjects were compared using independent samples t-tests for continuous variables and $\chi^{2}$ analysis for categorical data. To examine group differences in absolute spectral powers, repeated measures analysis of variance (ANOVA) was performed with the three grouped regions of electrode sites (frontal, centro-parietal, and posterior) as the within-subjects factor and group (FEP vs. HC) as the between-subjects factor. Because antipsychotic medication and benzodiazepines have been reported to be re- lated to several quantitative electroencephalography (QEEG) frequency powers, the baseline olanzapine-equivalent dose of antipsychotics and lorazepam-equivalent dose of benzodiazepine were used as covariates. ${ }^{29-31}$ After confirming the presence of significant group by region interactions, ANOVA with baseline olanzapine-equivalent dose of antipsychotics and lorazepam-equivalent dose of benzodiazepine as covariates was used to reveal specific regions showing group differences. A multiple regression analysis with the backward selection method was used to identify the factors that significantly predicted improvement in psychotic symptoms (i.e., PANSS scores at baseline minus those at the 1-year follow-up) and general functional status (i.e., GAF scores at the 1-year follow-up minus baseline scores) after a 1-year follow-up period with usual treatment. The anticipated predictive factors included absolute spectral power from regions showing significant group differences measured at baseline, demographic characteristics (age, sex, handedness, education years, IQ, DUP), mean daily olanzapine-equivalent dose of antipsychotics prescribed during the 1-year period, baseline PANSS positive or negative subscale scores, and baseline GAF scores. SPSS version 24 (IBM Corp., Armonk, NY, USA) was used for the statistical analysis. The threshold for statistical significance was set at $\mathrm{p}<0.05$.

\section{RESULTS}

\section{Demographic and clinical characteristics}

The demographic characteristics of the two groups (FEP and $\mathrm{HC}$ ) at baseline and the clinical characteristics of the FEP group at baseline and after a 1-year follow-up are presented in Table 1. The distribution of age, sex, handedness and education years did not differ between groups. However, the FEP group showed a lower IQ score than the HC group $(\mathrm{t}=-4.828$, $\mathrm{p}<0.001)$. The mean DUP of the FEP group was 5.7 months, and there was no difference in the mean olanzapine-equivalent dose of antipsychotics used at baseline and at the 1-year follow-up in patients with FEP. The scores on PANSS and GAF showed significant improvements in psychotic symptoms and general functional status after 1 year compared to scores measured at baseline.

\section{Quantitative electroencephalography (QEEG) results}

Figure 1 shows two-dimensional topographic maps and a comparison of the absolute power of each frequency across the FEP and HC groups. A repeated measures ANOVA with baseline olanzapine-equivalent dose of antipsychotics and lorazepam-equivalent dose of benzodiazepine as covariates revealed a significant main effect of group $(\mathrm{F}=8.145, \mathrm{p}=0.007)$, region $(\mathrm{F}=17.454, \mathrm{p}<0.001)$, and group by region interaction $(\mathrm{F}=3.362, \mathrm{p}=0.039)$ in the absolute power of the delta frequen- 
Table 1. Demographic and clinical characteristics of patients with first-episode psychosis (FEP) at baseline and after 1 year of follow-up and healthy control $(\mathrm{HC})$ subjects

\begin{tabular}{|c|c|c|c|c|c|c|}
\hline & \multicolumn{2}{|c|}{$\operatorname{FEP}(\mathrm{N}=24)$} & \multicolumn{2}{|c|}{$\mathrm{HC}(\mathrm{N}=24)$} & \multicolumn{2}{|c|}{ Statistical analysis* } \\
\hline & Mean & $\mathrm{SD}$ & Mean & SD & $\chi^{2}$ or $t$ & $\mathrm{p}$ \\
\hline Age (years) & 22.4 & 5.1 & 22.8 & 4.2 & -0.337 & 0.738 \\
\hline Sex (male/female) & \multicolumn{2}{|c|}{$10 / 14$} & \multicolumn{2}{|c|}{$9 / 15$} & 0.087 & 0.768 \\
\hline Handedness (right/left) & \multicolumn{2}{|c|}{$22 / 2$} & \multicolumn{2}{|c|}{$22 / 2$} & 0.000 & 1.000 \\
\hline Education (years) & 13.3 & 2.1 & 14.3 & 1.6 & -1.921 & 0.061 \\
\hline \multirow[t]{2}{*}{ IQ } & 98.0 & 13.7 & 116.9 & 13.3 & -4.828 & $<0.001^{\ddagger}$ \\
\hline & \multicolumn{2}{|c|}{ FEP at baseline $(\mathrm{N}=24)$} & \multicolumn{2}{|c|}{ FEP after 1-year $(\mathrm{N}=24)$} & & \\
\hline DUP (months) & 5.7 & 4.0 & - & - & - & - \\
\hline \multicolumn{7}{|l|}{ PANSS } \\
\hline Total scores & 69.1 & 14.0 & 46.8 & 10.1 & 6.238 & $<0.001^{\ddagger}$ \\
\hline Positive symptoms & 17.3 & 4.6 & 10.2 & 2.6 & 6.923 & $<0.001^{\ddagger}$ \\
\hline Negative symptoms & 17.3 & 4.6 & 12.8 & 4.1 & 3.743 & $0.001^{\ddagger}$ \\
\hline General symptoms & 34.5 & 7.1 & 23.8 & 5.0 & 5.678 & $<0.001^{\ddagger}$ \\
\hline GAF & 45.3 & 8.7 & 66.9 & 10.6 & -7.742 & $<0.001^{\ddagger}$ \\
\hline Antipsychotics dose ${ }^{\dagger}$ & 10.0 & 8.3 & 21.0 & 47.6 & -1.381 & 0.181 \\
\hline
\end{tabular}

*an independent t-test or Welch's $t$-test was used if the variances were not equal; $\chi^{2}$ analysis or Fisher's exact test was used for categorical data; a paired samples t-test was used to compare values obtained at baseline and after 1 year in FEP patients, ${ }^{\dagger}$ olanzapine-equivalent dose of antipsychotics, tthe mean difference is significant at the 0.005 level. SD: standard deviation, IQ: intelligence quotient, DUP: duration of untreated psychosis, PANSS: Positive and Negative Syndrome Scale, GAF: Global Assessment of Functioning

cy band. There was no significant group difference in the other frequency bands (i.e., theta, alpha, and beta). The results of ANCOVA to examine specific group differences in absolute spectral power in each region are summarized in Table 2. The delta absolute power in the frontal $(\mathrm{F}=7.586, \mathrm{p}=0.009)$ and posterior $(\mathrm{F}=7.915, \mathrm{p}=0.007)$ regions was significantly higher in patients with FEP than in HCs.

\section{Multiple regression analysis results}

In the multiple regression analysis, improvement in positive symptoms was predicted by higher baseline delta power in the posterior region $[\beta=0.031,95 \%$ confidence interval $(\mathrm{CI})=$ $0.002-0.059, \mathrm{p}=0.036]$ and higher baseline PANSS positive symptom subscale scores $(\beta=0.851,95 \% \mathrm{CI}=0.618-1.083$, $\mathrm{p}<$ $0.001)$. Lower baseline delta power in the frontal region $(\beta=$ $-0.025,95 \% \mathrm{CI}=-0.048--0.003, \mathrm{p}=0.028$ ), higher baseline PANSS negative symptom subscale scores $(\beta=0.912,95 \% \mathrm{CI}=0.609-$ $1.216, p<0.001)$, and female $\operatorname{sex}(\beta=4.643,95 \% \mathrm{CI}=1.621-7.665$, $\mathrm{p}=0.005$ ) predicted later improvement in negative symptoms. Improvement in general functional status was predicted by decreased baseline delta power in the frontal region $(\beta=-0.073$, $95 \% \mathrm{CI}=-0.138--0.009, \mathrm{p}=0.027$ ), increased baseline delta power in the posterior region $(\beta=0.189,95 \% \mathrm{CI}=0.084-0.294, \mathrm{p}=$ $0.001)$, lower $\mathrm{GAF}$ scores at baseline $(\beta=-1.135,95 \% \mathrm{CI}=-1.604-$ $-0.665, \mathrm{p}<0.001)$, and lower mean daily olanzapine-equivalent doses of antipsychotics used during the 1 year period $(\beta=$ $-0.096,95 \%$ CI=-0.171- $-0.021, \mathrm{p}=0.015)$ (Table 3, Figure 2).

\section{DISCUSSION}

This study aimed to identify biological predictors of 1-year symptomatic and functional improvement in patients with FEP using quantitative analysis of resting-state EEG. We found that delta absolute power at the frontal and posterior regions was significantly increased in patients with FEP compared to HCs. Moreover, the altered power of the delta frequency band was a significant predictor of symptomatic and functional improvement after 1 year of usual treatment in FEP patients. Higher delta power in the posterior region and more severe positive symptoms at baseline predicted later improvement of positive symptoms. Improvement of negative symptoms was associated with lower delta power in the frontal region, higher negative symptoms at baseline, and female sex. In addition, better general functional status after 1 year was predicted by lower delta power in the frontal region, higher delta power in the posterior region, poorer functional status at baseline, and a lower dose of antipsychotic medication used over the 1-year period.

In line with previous studies, we found significantly higher delta power in patients with FEP compared to HCs. ${ }^{17,32}$ It has been shown that the increased delta power found in psychosis patients reflected the pathophysiology of the disorder itself and was not related to patient characteristics such as the duration of the illness or the result of antipsychotic treatment. ${ }^{33,34}$ Previous studies suggested that altered delta activity found in 
psychosis patients possibly arose from dopamine synthesis capacity in the fronto-striato-thalamic loops. ${ }^{17,35,36}$ and promoted thalamic bursting, ${ }^{37}$ which is apparent from the beginning of psychotic disorder and is correlated with the severity of prodromal psychotic symptoms. ${ }^{35}$ In addition, this delta activity has been suggested as a fundamental feature of the cortico-

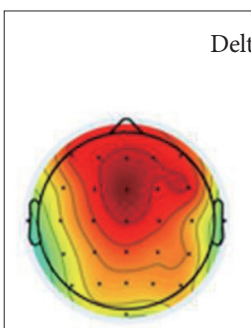

FEP

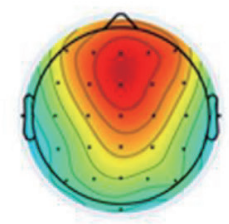

$\mathrm{HC}$

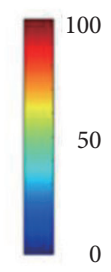

0

Alpha power

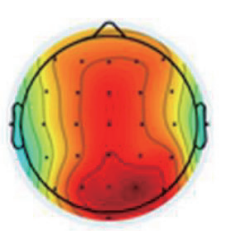

A

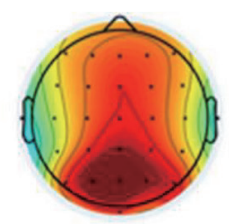

HC

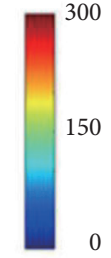

0
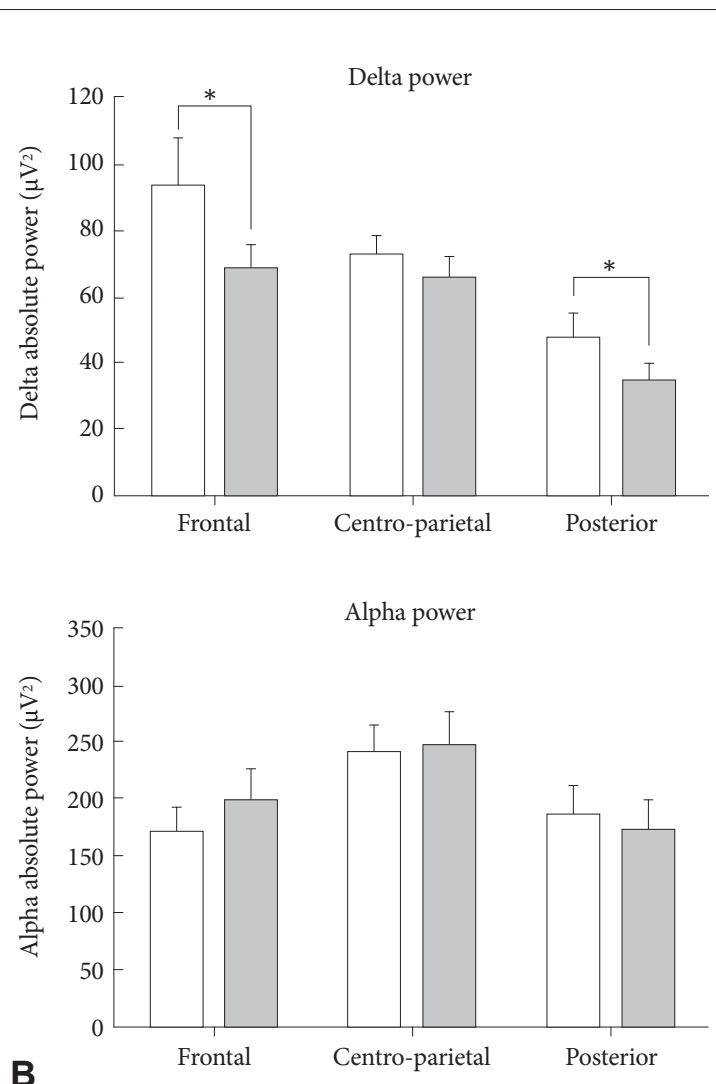

Beta power

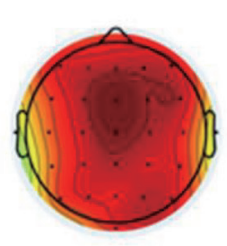

FEP

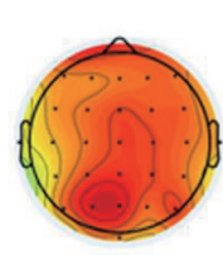

$\mathrm{HC}$
$\mathrm{HC}$
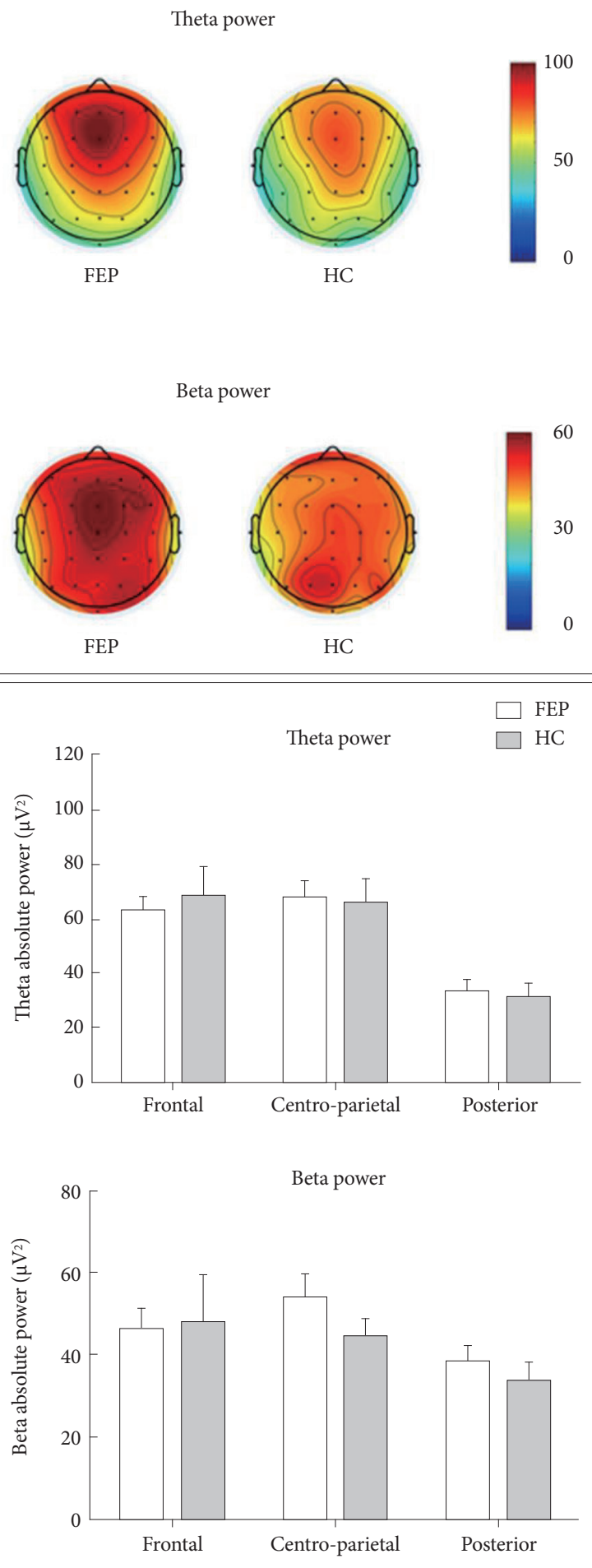

Figure 1. Group comparison results. A: Two-dimensional topographic maps of quantitative electroencephalography (QEEG) absolute power of each frequency band across patients with first-episode psychosis (FEP) and healthy control (HC) subjects. The color bar with numbers in the graph indicates QEEG absolute power $\left(\mu \mathrm{V}^{2}\right)$. B: Group comparison of QEEG absolute power in delta, theta, alpha, and beta frequencies at the frontal, centroparietal, and posterior sites. The vertical lines indicate standard errors. *indicates that the mean difference is significant at the 0.05 level. 
Table 2. Means and standard deviations (SDs) of electroencephalography (EEG) absolute spectral power in the frontal, centro-parietal, and posterior regions in patients with first-episode psychosis (FEP) and healthy control (HC) subjects

\begin{tabular}{|c|c|c|c|c|c|c|}
\hline & \multicolumn{2}{|c|}{$\operatorname{FEP}(\mathrm{N}=24)$} & \multicolumn{2}{|c|}{$\mathrm{HC}(\mathrm{N}=24)$} & \multicolumn{2}{|c|}{ Statistical analysis* } \\
\hline & Mean & SD & Mean & SD & $\mathrm{F}$ & $\mathrm{p}$ \\
\hline \multicolumn{7}{|l|}{ Delta frequency } \\
\hline Frontal region & 93.5 & 69.8 & 68.4 & 33.6 & 7.586 & $0.009^{\dagger}$ \\
\hline Centro-parietal region & 72.1 & 28.8 & 65.4 & 32.5 & 1.427 & 0.239 \\
\hline Posterior region & 47.2 & 37.5 & 34.6 & 24.3 & 7.915 & $0.007^{\dagger}$ \\
\hline \multicolumn{7}{|l|}{ Theta frequency } \\
\hline Frontal region & 62.7 & 26.0 & 68.8 & 52.1 & 0.013 & 0.908 \\
\hline Centro-parietal region & 67.9 & 29.7 & 65.5 & 43.6 & 0.220 & 0.642 \\
\hline Posterior region & 33.4 & 19.0 & 31.0 & 24.1 & 2.326 & 0.134 \\
\hline \multicolumn{7}{|l|}{ Alpha frequency } \\
\hline Frontal region & 240.6 & 114.0 & 247.6 & 136.0 & 0.066 & 0.799 \\
\hline Centro-parietal region & 185.0 & 123.9 & 171.7 & 131.2 & 0.130 & 0.720 \\
\hline Posterior region & 185.0 & 123.9 & 171.7 & 131.2 & 2.762 & 0.104 \\
\hline \multicolumn{7}{|l|}{ Beta frequency } \\
\hline Frontal region & 46.5 & 22.4 & 47.8 & 55.8 & 0.003 & 0.954 \\
\hline Centro-parietal region & 53.9 & 28.2 & 44.6 & 20.7 & 0.868 & 0.357 \\
\hline Posterior region & 38.3 & 18.6 & 33.4 & 22.4 & 2.636 & 0.112 \\
\hline
\end{tabular}

*analysis of variance with olanzapine-equivalent dose of antipsychotics and lorazepam-equivalent dose of benzodiazepine at baseline as covariates, ${ }^{\text {the }}$ mean difference is significant at the 0.05 level

Table 3. Results of multiple regression analysis with the backward selection method to predict symptomatic and functional improvement in patients with first-episode psychosis (FEP)

\begin{tabular}{|c|c|c|c|c|c|c|c|}
\hline \multirow{2}{*}{ Outcome variables } & \multirow{2}{*}{ Significant predictors } & \multirow{2}{*}{$\mathrm{R}^{2}$} & \multirow{2}{*}{ Beta } & \multirow{2}{*}{$\begin{array}{l}\text { Standardized } \\
\text { beta }\end{array}$} & \multirow{2}{*}{$\mathrm{p}$} & \multicolumn{2}{|c|}{$95 \% \mathrm{CI}$} \\
\hline & & & & & & Lower & Upper \\
\hline \multirow{2}{*}{$\begin{array}{l}\text { Improvement in PANSS } \\
\text { positive symptom subscale score }\end{array}$} & Delta power in the posterior region & 0.813 & 0.031 & 0.229 & 0.036 & 0.002 & 0.059 \\
\hline & $\begin{array}{l}\text { Baseline PANSS positive symptom } \\
\text { subscale score }\end{array}$ & & 0.851 & 0.778 & $<0.001$ & 0.618 & 1.083 \\
\hline \multirow{3}{*}{$\begin{array}{l}\text { Improvement in PANSS } \\
\text { negative symptom subscale score }\end{array}$} & Delta power in the frontal region & 0.754 & -0.025 & -0.302 & 0.028 & -0.048 & -0.003 \\
\hline & $\begin{array}{l}\text { Baseline PANSS negative symptom } \\
\text { subscale score }\end{array}$ & & 0.912 & 0.716 & $<0.001$ & 0.609 & 1.216 \\
\hline & Sex & & 4.643 & 0.397 & 0.005 & 1.621 & 7.665 \\
\hline \multirow[t]{4}{*}{ Improvement in GAF } & Delta power in the frontal region & 0.709 & -0.073 & -0.376 & 0.027 & -0.138 & -0.009 \\
\hline & Delta power in the posterior region & & 0.189 & 0.519 & 0.001 & 0.084 & 0.294 \\
\hline & Baseline GAF score & & -1.135 & 0.224 & $<0.001$ & -1.604 & -0.665 \\
\hline & Antipsychotic dose* & & -0.096 & -0.335 & 0.015 & -0.171 & -0.021 \\
\hline
\end{tabular}

${ }^{*}$ mean daily olanzapine-equivalent dose of antipsychotics. PANSS: Positive and Negative Syndrome Scale, GAF: Global Assessment of Functioning

thalamic circuit. ${ }^{38}$ Therefore, the increased delta power found in the current study may reflect the neurobiological correlate of the acute initiation of psychotic symptoms in FEP patients.

We found that decreased baseline delta power in the frontal region was associated with improvements in negative symptoms and general functioning after 1 year in patients with FEP. This finding is in line with previous studies that showed that increased delta power showed a positive correlation with high- er scores on the PANSS negative subscale and was a marker for negative symptoms in patients with psychotic disorder. ${ }^{18,19}$ In addition, Saletu et al. ${ }^{39}$ found that schizophrenia patients with predominant negative symptoms exhibited significantly increased delta activity in the frontal and bitemporal regions. These findings mostly refer to the cortical hypoactivation or hypofrontality found in patients with schizophrenia, as reflected in the reported correlation between increased delta activi- 


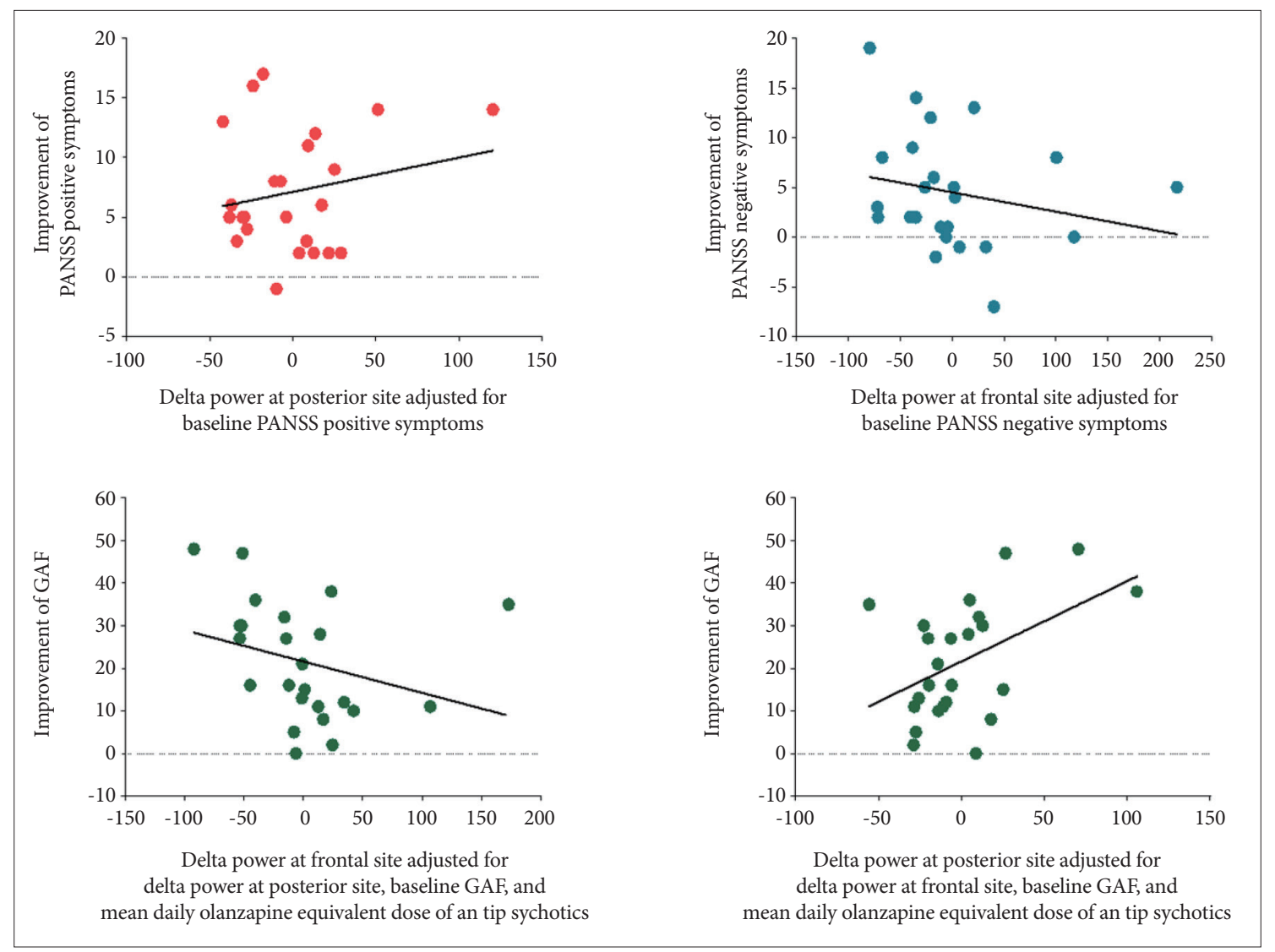

Figure 2. The partial correlations of the symptomatic and functional improvements in patients with first-episode psychosis (FEP) during the 1-year follow-up period with baseline delta absolute power in the frontal or posterior regions adjusted for controlling factors. PANSS: Positive and Negative Syndrome Scale, GAF: Global Assessment of Functioning.

ty at frontal regions and more severe negative symptoms as well as poorer general functional status. ${ }^{40}$

Interestingly, in this study, delta power measured in the posterior region predicted improvements in psychotic symptoms and general functional status in an opposite manner relative to delta power measured in the frontal region. That is, increased baseline delta power in the posterior region predicted later improvement of positive symptoms and general functional status. The findings of delta power in the posterior site may be explained by the relationship between the reduced slow wave density and worse positive symptoms in patients with schizophrenia. ${ }^{41}$ Moreover, the results of a study by Fryer et al., ${ }^{42}$ which showed that decreased low-frequency oscillations in the posterior regions of the brain were related to greater symptomatic severity in both early schizophrenia patients and clinical high risk groups, further supports the results of the current study.

Because the response to antipsychotic medications, their adverse effects, and the prognosis of FEP patients varies, ${ }^{2,5,6}$ it is important to decide the intensity of an intervention from the beginning of the treatment that will improve quality of life and maintain treatment adherence. Therefore, predicting the prognosis from the beginning of the treatment would provide valu- able information towards a personalized treatment that achieves better outcomes in FEP patients. Although attempts to predict the prognosis of FEP using various biomarkers such as brain imaging, ERPs, and brain neurochemistry has had impressive results, ${ }^{14,15,43}$ those modalities are expensive and labor-intensive methods for clinical application. In this context, resting-state EEG is a good candidate for clinical use due to its noninvasiveness, low cost, and easy application. In the current study, we found that the delta power of resting-state EEG predicted later improvement in psychotic symptoms and functional status. These results suggest that a quantitative analysis of restingstate EEG can be a putative biomarker to predict the prognosis of FEP and provide personalized treatment from the beginning of the treatment period in real clinical practice.

We must acknowledge several limitations of this study. First, the observational period was limited to a relatively short 1year period to find improvements in negative symptoms or general functional status, which should be augmented by future studies with longer follow-up periods. Second, because all patients except one were medicated at the time of EEG assessment, we could not completely rule out medication effects, which may have biased the results. Although we tried to con- 
trol for the dose of antipsychotics and benzodiazepines as covariates in the group comparison analyses, cautious interpretation is warranted. Third, EEG was measured only at baseline so that we could not show longitudinal changes in spectral powers in association with symptomatic or functional changes.

This study was the first to investigate whether the spectral power of resting-state EEG can be a predictive biomarker of a 1-year prognosis in FEP patients. Delta frequency power was increased in patients with FEP and predictive of symptomatic and functional improvements. The results of the current study not only suggest that delta frequency power is associated with pathophysiological mechanisms regardless of the duration of illness or medication effect but also elucidate the possibility of delta frequency power as a putative predictor of short-term prognosis from the beginning of a psychotic disorder. Using resting-state EEG, which is cost effective and easily applied in clinical practice, personalized medicine to optimize the intensity of acute and maintenance treatment for FEP patients would be further aided.

\section{Acknowledgments}

This research was supported by the Brain Research Program and the Basic Science Research Program through the National Research Foundation of Korea (NRF), funded by the Ministry of Science, ICT \& Future Planning (Grant no. 2017M3C7A1029610, 2016R1E1A1A02921618, 2019R1C1C1002457).

\section{Conflicts of Interest}

The authors have no potential conflicts of interest to disclose.

\section{Author Contributions}

Conceptualization: Rinvil Renaldi, Minah Kim. Data curation: Tak Hyung Lee, Yoo Bin Kwak. Fornal analysis: Rinvil Renaldi, Minah Kim, Tak Hyung Lee. Funding acquisition: Minah Kim, Jun Soo Kwon. Investigation: Rinvil Renaldi, Minah Kim, Tak Hyung Lee, Yoo Bin Kwak, Andi J. Tanra, Jun Soo Kwon. Methodology: Minah Kim, Tak Hyung Lee, Yoo Bin Kwak. Project administration: Rinvil Renaldi, Minah Kim, Andi J. Tanra, Jun Soo Kwon. Resources: Minah Kim, Jun Soo Kwon. Software: Rinvil Renaldi, Minah Kim, Tak Hyung Lee, Yoo Bin Kwak. Supervision: Minah Kim, Andi J. Tanra, Jun Soo Kwon. Validation: Rinvil Renaldi, Minah Kim, Tak Hyung Lee, Yoo Bin Kwak, Andi J. Tanra, Jun Soo Kwon. Visualization: Rinvil Renaldi, Minah Kim, Tak Hyung Lee. Writing_original draft: Rinvil Renaldi, Minah Kim. Writing_-review \& editing: Andi J. Tanra, Jun Soo Kwon.

\section{ORCID iDs}

$\begin{array}{ll}\text { Minah Kim } & \text { https://orcid.org/0000-0001-8668-0817 } \\ \text { Rinvil Renaldi } & \text { https://orcid.org/0000-0001-5792-0420 }\end{array}$

\section{REFERENCES}

1. Suvisaari J, Mantere O, Keinanen J, Mantyla T, Rikandi E, Lindgren M, et al. Is it possible to predict the future in first-episode psychosis? Front Psychiatry 2018;9:580.

2. Lieberman JA, Perkins D, Belger A, Chakos M, Jarskog F, Boteva K, et al. The early stages of schizophrenia: speculations on pathogenesis, pathophysiology, and therapeutic approaches. Biol Psychiatry 2001;50:884897.

3. Marshall M, Lewis S, Lockwood A, Drake R, Jones P, Croudace T. Association between duration of untreated psychosis and outcome in cohorts of first-episode patients: a systematic review. Arch Gen Psychiatry
2005;62:975-983.

4. Perkins DO, Gu H, Boteva K, Lieberman JA. Relationship between duration of untreated psychosis and outcome in first-episode schizophrenia: a critical review and meta-analysis. Am J Psychiatry 2005;162:17851804.

5. Staring AB, Mulder CL, Duivenvoorden HJ, de Haan L, van der Gaag M. Fewer symptoms vs. more side-effects in schizophrenia? Opposing pathways between antipsychotic medication compliance and quality of life. Schizophr Res 2009;113:27-33.

6. Bebbington PE, Angermeyer M, Azorin JM, Marwaha S, Marteau F, Toumi M. Side-effects of antipsychotic medication and health-related quality of life in schizophrenia. Acta Psychiatr Scand Suppl 2009;119:2228.

7. Dayabandara M, Hanwella R, Ratnatunga S, Seneviratne S, Suraweera C, de Silva VA. Antipsychotic-associated weight gain: management strategies and impact on treatment adherence. Neuropsychiatr Dis Treat 2017; 13:2231-2241.

8. Santesteban-Echarri O, Paino M, Rice S, Gonzalez-Blanch C, McGorry $\mathrm{P}$, Gleeson J, et al. Predictors of functional recovery in first-episode psychosis: a systematic review and meta-analysis of longitudinal studies. Clin Psychol Rev 2017;58:59-75.

9. Compton MT, Berez C, Walker EF. The relative importance of family history, gender, mode of onset, and age at onsetin predicting clinical features of first-episode psychotic disorders. Clin Schizophr Relat Psychoses 2017;11:143-150.

10. Moos RH, McCoy L, Moos BS. Global assessment of functioning (GAF) ratings: determinants and role as predictors of one-year treatment outcomes. J Clin Psychol 2000;56:449-461.

11. Ayesa-Arriola R, Rodriguez-Sanchez JM, Perez-Iglesias R, GonzalezBlanch C, Pardo-Garcia G, Tabares-Seisdedos R, et al. The relevance of cognitive, clinical and premorbid variables in predicting functional outcome for individuals with first-episode psychosis: a 3 year longitudinal study. Psychiatry Res 2013;209:302-308.

12. Rodrigues-Amorim D, Rivera-Baltanas T, Lopez M, Spuch C, Olivares JM, Agis-Balboa RC. Schizophrenia: a review of potential biomarkers. J Psychiatr Res 2017;93:37-49.

13. Lieberman J, Chakos M, Wu H, Alvir J, Hoffman E, Robinson D, et al. Longitudinal study of brain morphology in first episode schizophrenia. Biol Psychiatry 2001;49:487-499.

14. Wood SJ, Berger GE, Lambert M, Conus P, Velakoulis D, Stuart GW, et al. Prediction of functional outcome 18 months after a first psychotic episode: a proton magnetic resonance spectroscopy study. Arch Gen Psychiatry 2006;63:969-976.

15. Lho SK, Kim M, Lee TH, Kwak YB, Kwon JS. Predicting prognosis in patients with first-episode psychosis using auditory P300: a 1-year follow-up study. Clin Neurophysiol 2018;130:46-54.

16. Nuwer MR. Clinical use of QEEG. Clin Neurophysiol 2003;114:2225.

17. Boutros NN, Arfken C, Galderisi S, Warrick J, Pratt G, Iacono W. The status of spectral EEG abnormality as a diagnostic test for schizophrenia. Schizophr Res 2008;99:225-237.

18. Gschwandtner U, Zimmermann R, Pflueger MO, Riecher-Rossler A, Fuhr P. Negative symptoms in neuroleptic-naive patients with first-episode psychosis correlate with QEEG parameters. Schizophr Res 2009; 115:231-236.

19. Gross A, Joutsiniemi SL, Rimon R, Appelberg B. Correlation of symptom clusters of schizophrenia with absolute powers of main frequency bands in quantitative EEG. Behav Brain Funct 2006;2:23.

20. Manchanda R, Malla A, Harricharan R, Cortese L, Takhar J. EEG abnormalities and outcome in first-episode psychosis. Can J Psychiatry 2003;48:722-726.

21. Manchanda R, Norman R, Malla A, Harricharan R, Northcott S, Richard J. Electroencephalographic abnormalities and 5-year outcome in first-episode psychosis. Can J Psychiatry 2014;59:285-288.

22. Manchanda R, Norman R, Malla A, Harricharan R, Northcott S. EEG abnormalities and 3-year outcome in first episode psychosis. Acta Psy- 
chiatr Scand 2008;117:277-282.

23. Manchanda R, Norman R, Malla A, Harricharan R, Takhar J, Northcott S. EEG abnormalities and two year outcome in first episode psychosis. Acta Psychiatr Scand 2005;111:208-213.

24. Gardner DM, Murphy AL, O’Donnell H, Centorrino F, Baldessarini RJ. International consensus study of antipsychotic dosing. Am J Psychiatry 2010;167:686-693.

25. Ashton CH. Benzodiazepines: How They Work and How to Withdraw. Newcastle: Newcastle University; 2006

26. Yum T, Park Y, Oh K, Kim J, Lee Y. The Manual of Korean-Wechsler Adult Intelligence Scale. Seoul: Korean Guidance Press; 1992.

27. Annett $M$. The binomial distribution of right, mixed and left handedness. Q J Exp Psychol 1967;19:327-333.

28. Delorme A, Makeig S. EEGLAB: an open source toolbox for analysis of single-trial EEG dynamics including independent component analysis. J Neurosci Methods 2004;134:9-21.

29. Hyun J, Baik MJ, Kang UG. Effects of psychotropic drugs on quantitative EEG among patients with schizophrenia-spectrum disorders. Clin Psychopharmacol Neurosci 2011;9:78-85.

30. Moon SY, Choi YB, Jung HK, Lee YI, Choi SH. Increased frontal gamma and posterior delta powers as potential neurophysiological correlates differentiating posttraumatic stress disorder from anxiety disorders. Psychiatry Investig 2018;15:1087-1093.

31. Staner L, Ertle S, Boeijinga P, Rinaudo G, Arnal MA, Muzet A, et al. Next-day residual effects of hypnotics in DSM-IV primary insomnia: a driving simulator study with simultaneous electroencephalogram monitoring. Psychopharmacology (Berl) 2005;181:790-798.

32. Clementz BA, Sponheim SR, Iacono WG, Beiser M. Resting EEG in firstepisode schizophrenia patients, bipolar psychosis patients, and their first-degree relatives. Psychophysiology 1994;31:486-494.

33. Sponheim SR, Clementz BA, Iacono WG, Beiser M. Resting EEG in firstepisode and chronic schizophrenia. Psychophysiology 1994;31:37-43.
34. Nagase Y, Okubo Y, Toru M. Electroencephalography in schizophrenic patients: comparison between neuroleptic-naive state and after treatment. Biol Psychiatry 1996;40:452-456.

35. Dandash O, Pantelis C, Fornito A. Dopamine, fronto-striato-thalamic circuits and risk for psychosis. Schizophr Res 2017;180:48-57.

36. Howes OD, Bose SK, Turkheimer F, Valli I, Egerton A, Valmaggia LR, et al. Dopamine synthesis capacity before onset of psychosis: a prospective [18F]-DOPA PET imaging study. Am J Psychiatry 2011;168:1311-1317.

37. Lisman JE, Pi HJ, Zhang Y, Otmakhova NA. A thalamo-hippocampalventral tegmental area loop may produce the positive feedback that underlies the psychotic break in schizophrenia. Biol Psychiatry 2010;68:1724.

38. Neske GT. The slow oscillation in cortical and thalamic networks: mechanisms and functions. Front Neural Circuits 2015;9:88

39. Saletu B, Kufferle B, Anderer P, Grunberger J, Steinberger K. EEG-brain mapping in schizophrenics with predominantly positive and negative symptoms. Comparative studies with remoxipride/haloperidol. Eur Neuropsychopharmacol 1990;1:27-36.

40. Gattaz WF, Mayer S, Ziegler P, Platz M, Gasser T. Hypofrontality on topographic EEG in schizophrenia. Correlations with neuropsychological and psychopathological parameters. Eur Arch Psychiatry Clin Neurosci 1992;241:328-332.

41. Kaskie RE, Gill KM, Ferrarelli F. Reduced frontal slow wave density during sleep in first-episode psychosis. Schizophr Res 2019;206:318-324.

42. Fryer SL, Roach BJ, Wiley K, Loewy RL, Ford JM, Mathalon DH. Reduced amplitude of low-frequency brain oscillations in the psychosis risk syndrome and early illness schizophrenia. Neuropsychopharmacology 2016;41:2388-2398.

43. Lieberman J, Jody D, Geisler S, Alvir J, Loebel A, Szymanski S, et al. Time course and biologic correlates of treatment response in first-episode schizophrenia. Arch Gen Psychiatry 1993;50:369-376. 